\title{
Preparation of Activated Carbon from Bagasse by Microwave-Assisted Phosphoric Acid Activation
}

\author{
Suthatip SINYOUNG ${ }^{1}$, Weerawut CHAIWAT ${ }^{2}$ and \\ Kittipong KUNCHARIYAKUN ${ }^{3,4, *}$
}

\author{
${ }^{I}$ Department of Civil Engineering, Faculty of Engineering, Prince of Songkla University, \\ Songkhla 90112, Thailand \\ ${ }^{2}$ Department of Chemical Engineering, Faculty of Engineering, Mahidol University, \\ Nakhon Pathom 73170, Thailand \\ ${ }^{3}$ School of Engineering and Technology, Walailak University, Nakhon Si Thammarat 80160, Thailand \\ ${ }^{4}$ Center of Excellence in Sustainable Disaster Management, Walailak University, \\ Nakhon Si Thammarat 80160, Thailand
}

('Corresponding author’s e-mail: kunchariyakun.k@gmail.com, kittipong.ku@wu.ac.th)

Received: 31 March 2021, Revised: 9 May 2021, Accepted: 16 May 2021

\begin{abstract}
This research focuses on the utilization of bagasse as activated carbon (AC) under microwaveassisted phosphoric acid activation. The $\mathrm{AC}$ was activated using various frequencies of microwave energy combined with phosphoric acid before the carbonization process. Results indicated that the AC obtained from bagasse under microwave-assisted phosphoric acid had improved properties, i.e. fixed carbon, surface area, and iodine adsorption capacity. However, the loss of AC properties could be attributed to microwave energy exceeding a limit of $800 \mathrm{~W}$. The optimum activated condition in this research was the use of microwave energy $500 \mathrm{~W}$ assisted phosphoric acid, which had fixed carbon, surface area, and iodine adsorption capacity at $88.34 \pm 0.67 \%, 781 \mathrm{~m}^{2} / \mathrm{g}$, and $852 \pm 6.0 \mathrm{mg} / \mathrm{g}$, respectively.
\end{abstract}

Keywords: Activated carbon, Bagasse, Microwave energy, Phosphoric acid

\section{Introduction}

Activated carbon (AC) is well known as a porous material that can adsorb various matters or pollutants in any state. The applications of AC include medical treatment [1], energy storage [2], water and wastewater treatment [3], and flue gas treatment and adsorption [4]. The use of AC is increasing every year as it is widely used in a variety of applications [5]. The properties of AC can be derived from its high surface area, well-developed internal structure, and presence of various functional groups, which depend on the raw materials and preparation methods. For the preparation methods, activation is the key process to obtain high-quality $\mathrm{AC}$. There are 2 common activation processes: physical activation, e.g. steam and carbon dioxide, and chemical activation, e.g. $\mathrm{KOH}, \mathrm{NaOH}, \mathrm{ZnCl}_{2}$, and $\mathrm{H}_{3} \mathrm{PO}_{4}$. Among both activation processes, chemical activation was noted to be the preferred method because the activation temperature required is relatively low, compared with physical activation [6,7].

Microwave energy is one of the most popular methods used in physical activation, due to this type of energy providing a uniform temperature distribution, a rapid temperature rise, in addition, to being energy-saving [8-10]. The applications of microwave-induced chemical activation have been extensively studied over recent years. [11] noted that the activation via microwave-assisted $\mathrm{KOH}$ improved the BET surface area of starch-derived spherical carbon from 8.9 to $616.8 \mathrm{~m}^{2} \mathrm{~g}^{-1}$. [12] also demonstrated that the AC prepared from cotton stalks by microwave-assisted $\mathrm{ZnCl}_{2}$ showed the high adsorption ability of 
methylene blue. Although the utilization of microwave energy as an activation source can enhance the properties of AC, microwave energy that is too high will lead to the destruction of the pore structure of $\mathrm{AC}$, resulting in inefficiency adsorption [13]. Finding the appropriate microwave energy conditions for each raw material is necessary.

Bagasse is a by-product of the sugar industry, which is around $30 \%$ of the entire plant [14]. The main compounds of bagasse are lignin and cellulose. This leads to bagasse being an effective resource for cheap AC production if prepared under controlled conditions or with appropriate treatments [15]. Hence, in terms of the application of bagasse as $\mathrm{AC}$, this can decrease the volume of agriculture waste and simultaneously produce a valuable adsorbent with cheaper costs than traditional AC [16,17]. In this sense, the focus of this study was to prepare low-cost activated carbon from bagasse by microwave-assisted phosphoric acid activation before the carbonization process. The appropriate activated condition was evaluated on yield, fixed carbon, surface area, functional groups and adsorption capacity.

\section{Materials and methods}

\section{Materials}

Bagasse was collected from the Prachuap Sugar Industry, Co., Ltd., Kanchanaburi, Thailand. To control for the consistency of bagasse for this study, the whole quantity requirement of bagasse was estimated and collected at one time. The components of bagasse, which consisted of extractive free $3.09 \%$, cellulose $49.31 \%$, lignin $23.21 \%$, and hemicellulose $24.39 \%$ wt. (dry basis), which were carried out using TAPPI (Technical Association of the Pulp and Paper Industry) methods [18-21]. The received bagasse was firstly washed with deionized water to remove any dust and soil and then dried in an electric oven at a temperature of $90{ }^{\circ} \mathrm{C}$ overnight. The dried bagasse was ground and sieved to produce particles smaller than $250 \mu \mathrm{m}$ (Sieve No. 60). All chemical reagents used in this research were of an analytical grade, such as iodine and phosphoric acid $\left(\mathrm{H}_{3} \mathrm{PO}_{4}\right)$.

\section{Determination of optimum carbonized temperature}

To determine the optimum carbonized temperature, $2.0 \mathrm{~g}$ of ground bagasse was placed in a crucible and then heated using an electric furnace at a rate of $10^{\circ} \mathrm{C} / \mathrm{min}$, under $\mathrm{N}_{2}$ atmosphere, as shown in Figure 1. When the temperatures reached the desired temperatures, ranging from $400-800{ }^{\circ} \mathrm{C}$, the heat was maintained for $1 \mathrm{~h}$. The fixed carbon contents and the nature of the chemical bonds of the carbonized samples were examined using Thermogravimetric analysis (TGA, TGA8000, Perkin-Elmer, USA) and Fourier transform infrared spectroscopy (FTIR, Model Bruker/Tensor27 method.), respectively. The yields of the carbonized samples based on the dry samples were calculated as shown in Eq. (1). The heating temperature that provided the optimum fixed carbon and yield was selected to prepare the activated carbon in section 2.3 .

Yield $($ wt. $\%$, dry basis $)=\frac{W_{f}}{W_{i}} \times 100$

$\mathrm{W}_{\mathrm{f}}$ is the weight of carbonized samples $(\mathrm{g})$ and $\mathrm{W}_{\mathrm{i}}$ is the weight of raw ground bagasse $(\mathrm{g})$. 

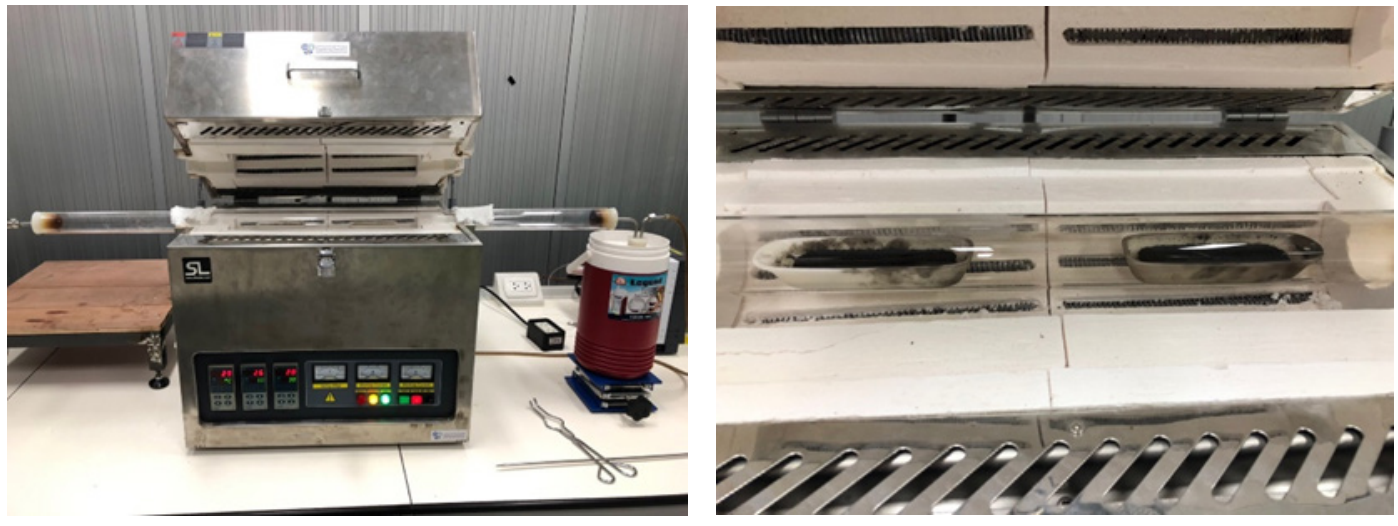

Figure 1 Experiment set up for carbonization process.

\section{Microwave-assisted acid pretreatment of bagasse before carbonization}

To prepare activated carbon (AC) from bagasse, $2.0 \mathrm{~g}$ of the ground bagasse was immersed in $40 \%$ phosphoric acid with a solid: Liquid ratio of 1 for $24 \mathrm{~h}$. The immersed samples were then subjected to activation via microwave power of $0,200,500$, and 800 watts for $60 \mathrm{~s}$. After that, the activated samples were rinsed with DI water to remove any excess solution and dried in an electric oven at $110^{\circ} \mathrm{C}$ for $24 \mathrm{~h}$. The activated conditions are summarized in Table 1. The samples were heated using an electric furnace with the optimum conditions from section 2.2. The activated carbon samples obtained were examined for yield, fixed carbon, FTIR, scanning electron microscopy (SEM, Model Apreo), Brunauer-Emmett-Teller (BET, Model ASAP2460), and iodine absorption capacity. All experiments, i.e., yield, fixed carbon, and iodine absorption capacity, were performed in triplicate.

For iodine absorption capacity analysis, the experiments were performed following ASTM D460714. The activated carbon obtained was ground until it passed through a 100-mesh screen. The ground AC was dried at $120^{\circ} \mathrm{C}$ for $3 \mathrm{~h}$ and then kept in a desiccator until cool. $1 \mathrm{~g}$ of dried ground $\mathrm{AC}$ was placed into a $250 \mathrm{~mL}$ Erlenmeyer flask, and then $10 \mathrm{~mL}$ of $5 \%$ hydrochloric acid $(\mathrm{HCl})$ was added. Each flask was swirled gently until the $\mathrm{AC}$ was wet and then boiled for $30 \pm 2 \mathrm{~s}$ for sulfur removal. The flask was cooled to room temperature. $100 \mathrm{~mL}$ of $0.1 \mathrm{~N}$ iodine solution was added and shaken for $30 \pm 1 \mathrm{~s}$. The solution was then filtrated to separate solid and liquid. $50 \mathrm{~mL}$ of filtrated solution was added to the 250 $\mathrm{mL}$ Erlenmeyer flask and titrated with $0.1 \mathrm{~N}$ sodium thiosulfate solution until the solution was a pale yellow color. After that, $2 \mathrm{~mL}$ of the starch indicator was added and continuously titrated with $0.1 \mathrm{~N}$ sodium thiosulfate solution until it became a colorless solution. The concentration of the sodium thiosulfate solution was recorded and calculated, as shown in Eqs. (2) - (4).

$\frac{X}{M}=\left[\frac{D F \times B \times S}{M}\right]$

$D F=\frac{(I+H)}{F}$

$C=\frac{\left(N_{1}+S\right)}{F}$

where $\quad \mathrm{X} / \mathrm{M}$ is iodine absorbed per gram of carbon $(\mathrm{mg} / \mathrm{g})$.

$\mathrm{S}$ is the volume of sodium thiosulfate $(\mathrm{mL})$.

$M$ is carbon used (g).

DF is dilution factor.

I is the volume of iodine solution $(\mathrm{mL})$. 
http://wjst.wu.ac.th

$\mathrm{H}$ is the volume of $5 \% \mathrm{HCl}(\mathrm{mL})$.

$\mathrm{F}$ is the volume of filtrate $(\mathrm{mL})$.

$\mathrm{C}$ is the concentration of residual filtrate $(\mathrm{N})$.

$\mathrm{N}_{1}$ is the concentration of sodium thiosulfate $(\mathrm{N})$.

Table 1 The summarization of activated conditions in this research.

\begin{tabular}{cc}
\hline Symbols & \multicolumn{1}{c}{ Details } \\
\hline $\mathrm{C}$ & Carbonization without activated process \\
PC & Activated by $\mathrm{H}_{3} \mathrm{PO}_{4}$ and then carbonization \\
PM200C & Activated by $\mathrm{H}_{3} \mathrm{PO}_{4}$ with a microwave power of $200 \mathrm{~W}$ and then carbonization \\
PM500C & Activated by $\mathrm{H}_{3} \mathrm{PO}_{4}$ with a microwave power of $500 \mathrm{~W}$ and then carbonization \\
PM800C & Activated by $\mathrm{H}_{3} \mathrm{PO}_{4}$ with a microwave power of $800 \mathrm{~W}$ and then carbonization \\
\hline
\end{tabular}

\section{Results and discussion}

\section{Characteristics of carbonized bagasse}

In this investigation, the appropriate carbonized condition for the bagasse was determined in the range of $400-800{ }^{\circ} \mathrm{C}$, through yield, fixed carbon content, and FTIR analysis. Figure 2 exhibits the yields and fixed carbon contents at various temperatures, which pronounced that fixed carbon contents increased with an increasing temperature of up to $600{ }^{\circ} \mathrm{C}$, whereas the yields decreased. In terms of FTIR analysis, a broad peak was found at $\approx 3450 \mathrm{~cm}^{-1}$ indicating $-\mathrm{OH}$ stretching vibration mode of hydroxyl functional groups [22], as represented in Figure 3. The peak at $1606 \mathrm{~cm}^{-1}$ was characterized as the $\mathrm{C}=\mathrm{O}$ stretching vibration of lactonic and carbonyl groups [23,24]. Meanwhile, the peak appearing at approximately $1080 \mathrm{~cm}^{-1}$ represented the C-O vibrations of various oxygen-containing groups [25]. The band in the range of $800-500 \mathrm{~cm}^{-1}$ could be attributed to $\mathrm{C}-\mathrm{H}$ and $\mathrm{C}=\mathrm{CH}_{2}$ stretching vibration in aromatic structures [26]. The increase in carbonized temperatures led to the disappearance of the peak at $1606 \mathrm{~cm}^{-1}$ on the carbonized sample at $800^{\circ} \mathrm{C}$. This finding might be related to the reduction of fixed carbon content at high temperatures (above $600{ }^{\circ} \mathrm{C}$ ). Previous research studies noted that the adsorption capacity not only depends on the surface area, pores volume, and types of pores but also correlates with the concentration of fixed carbon [12,27]. Relatively high fixed carbon provides a high adsorption capacity. Hence, this indicated that the optimum carbonized temperature of this study was $600{ }^{\circ} \mathrm{C}$, giving the yield and fixed carbon contents as 26.63 and $83.95 \%$ by weight, respectively. 
http://wjst.wu.ac.th
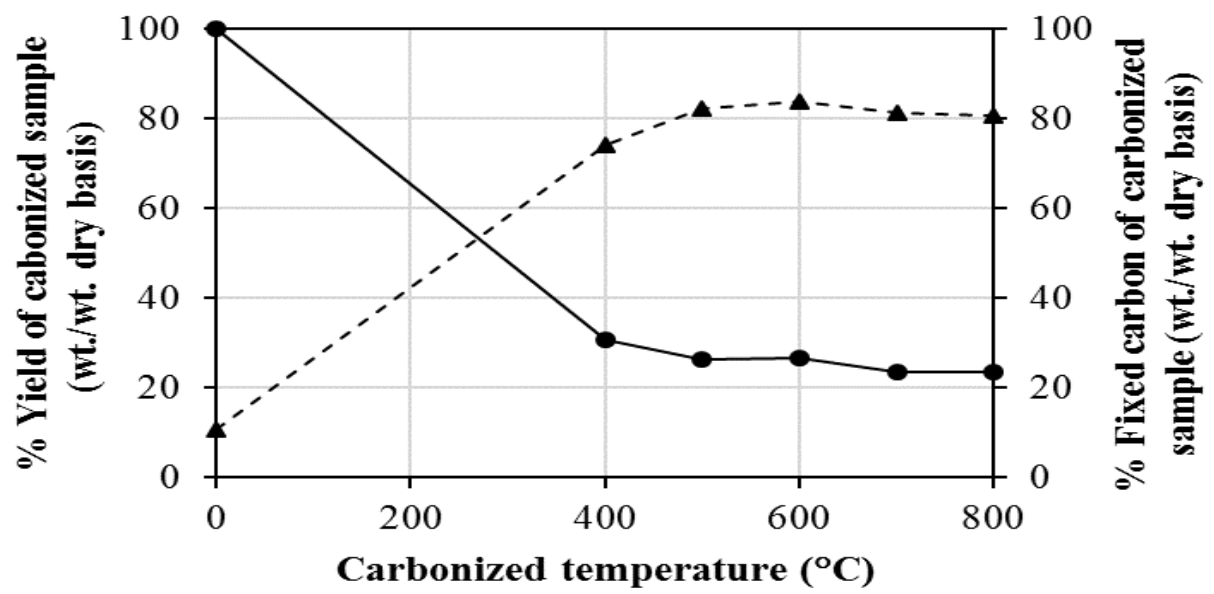

Figure 2 Yield and fixed carbon contents of carbonized samples.

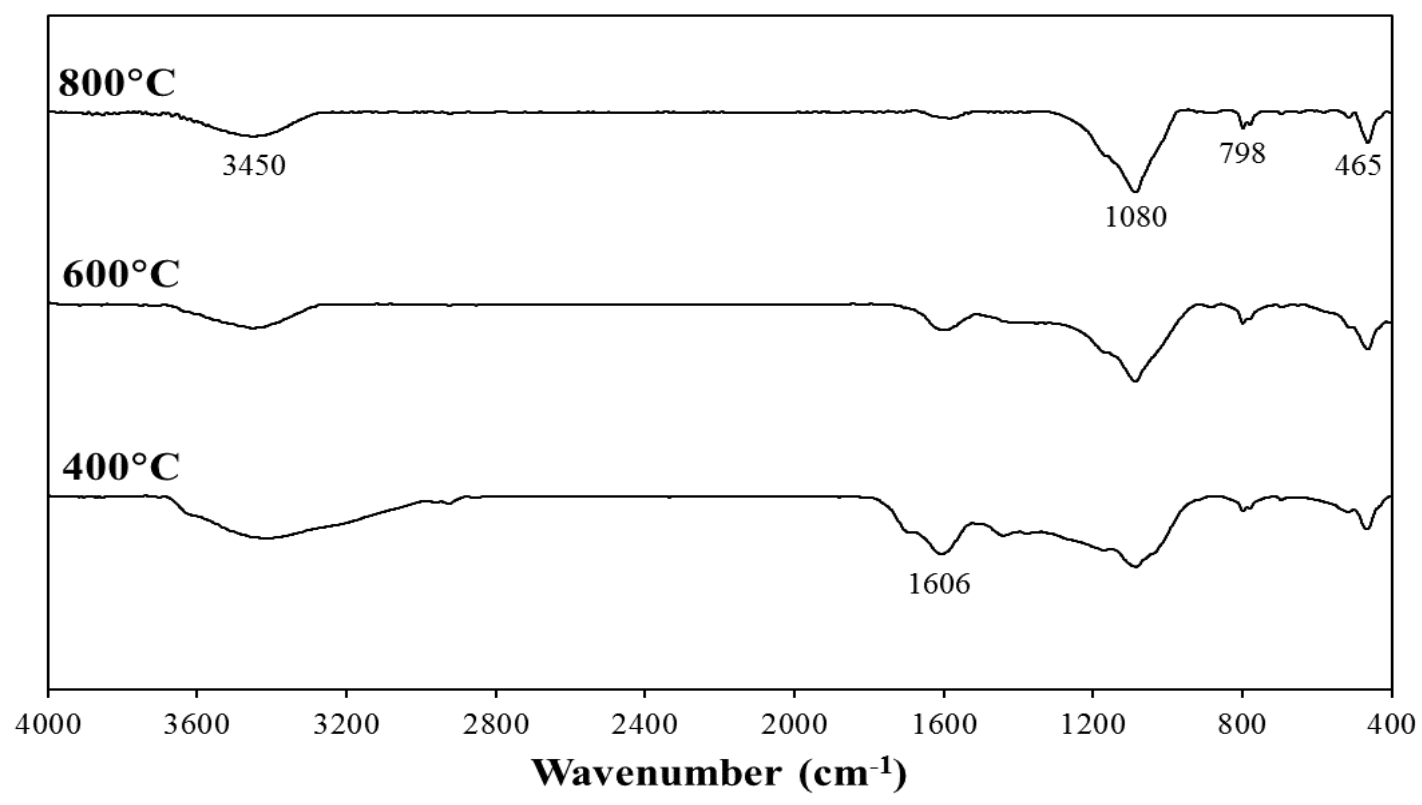

Figure 3 FTIR patterns of carbonized samples.

\section{Characteristics of activated carbon from bagasse}

Yield and fixed carbon content

Regarding the previous investigation, the carbonized temperature of $600{ }^{\circ} \mathrm{C}$ for $1 \mathrm{~h}$ exhibited the optimum condition, consequently, this was applied to synthesize the activated carbon in this section. The properties of the AC obtained were enhanced by pretreatment with $40 \%$ phosphoric acid and microwave energy in the range of $200-800 \mathrm{~W}$, before the carbonized process. Figure 4 shows the yield and fixed carbon contents of activated carbon from bagasse by microwave-assisted phosphoric acid activation. Results showed that the percentage of yield increased when the bagasse was activated by phosphoric acid, as illustrated in Figure 4(a). This was due to the formation of phosphocarbonaceous species and volatile 
phosphorous compounds on the surface of bagasse [7,28]. The influence of microwave energy led to a gradual decrease in the yields again due to the thermal degradation of some volatile matter [7,29]. In terms of fixed carbon, this was found to increase with the activation processes, as shown in Figure 4(b). This means that the formation of phosphocarbonaceous species and volatile phosphorous compounds on the surface of bagasse acted in the protection of the carbon skeleton [29]. The increase in microwave energy can contribute to obtaining more active sites on the samples [12]. However, the fixed carbon loss was attributed to the microwave energy increase to $800 \mathrm{~W}$. This means that some phosphocarbonaceous species and volatile phosphorous compounds were eliminated.

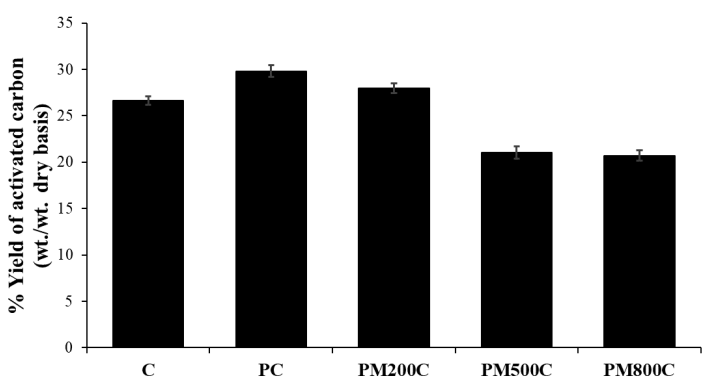

(a)

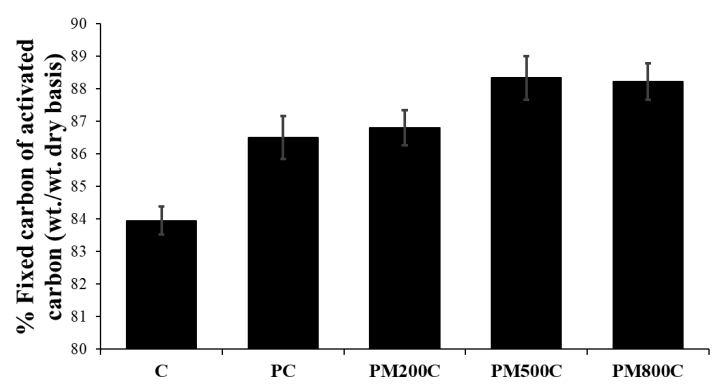

(b)

Figure 4 Yield and fixed carbon contents of activated carbon. (a) Yield and (b) fixed carbon contents.

\section{Fourier transform infrared spectrum (FTIR)}

FTIR spectrum was used to identify the functional groups on the surface of the samples. The samples before and after the carbonized process are shown in Figures 5 and 6, respectively. Regarding Figure 5, it shows that there is a small change between the raw BG and the activated BG. All samples exhibited 2 obvious peaks at the broad peak at $\approx 3450$ and $1080 \mathrm{~cm}^{-1}$, and this could be attributed to $-\mathrm{OH}$ stretching vibration mode of hydroxyl functional groups and $\mathrm{C}-\mathrm{O}$ vibrations of various oxygen-containing groups, respectively. The PM800 sample reveals very low intensity at $1080 \mathrm{~cm}^{-1}$, which may imply a loss of functional groups. This finding is related to yield and fixed carbon loss results, as shown in Figure 3(a).

After the carbonized process, the peak at $\approx 3450 \mathrm{~cm}^{-1}$ disappeared for all samples, as given in Figure 6. All samples have 4 similar peaks, i.e. at $1606,1080 \mathrm{~cm}^{-1}$, and the band range of $800-500 \mathrm{~cm}^{-1}$. The peaks at 1606 and $1080 \mathrm{~cm}^{-1}$ were attributed to $\mathrm{C}=\mathrm{O}$ and $\mathrm{C}-\mathrm{O}$ vibrations, respectively, while the band range of $800-500 \mathrm{~cm}^{-1}$ was $\mathrm{C}-\mathrm{H}$ and $\mathrm{C}=\mathrm{CH}_{2}$ stretching vibrations. This indicated that the activation process seemed to have no significant impact on the functional groups. 


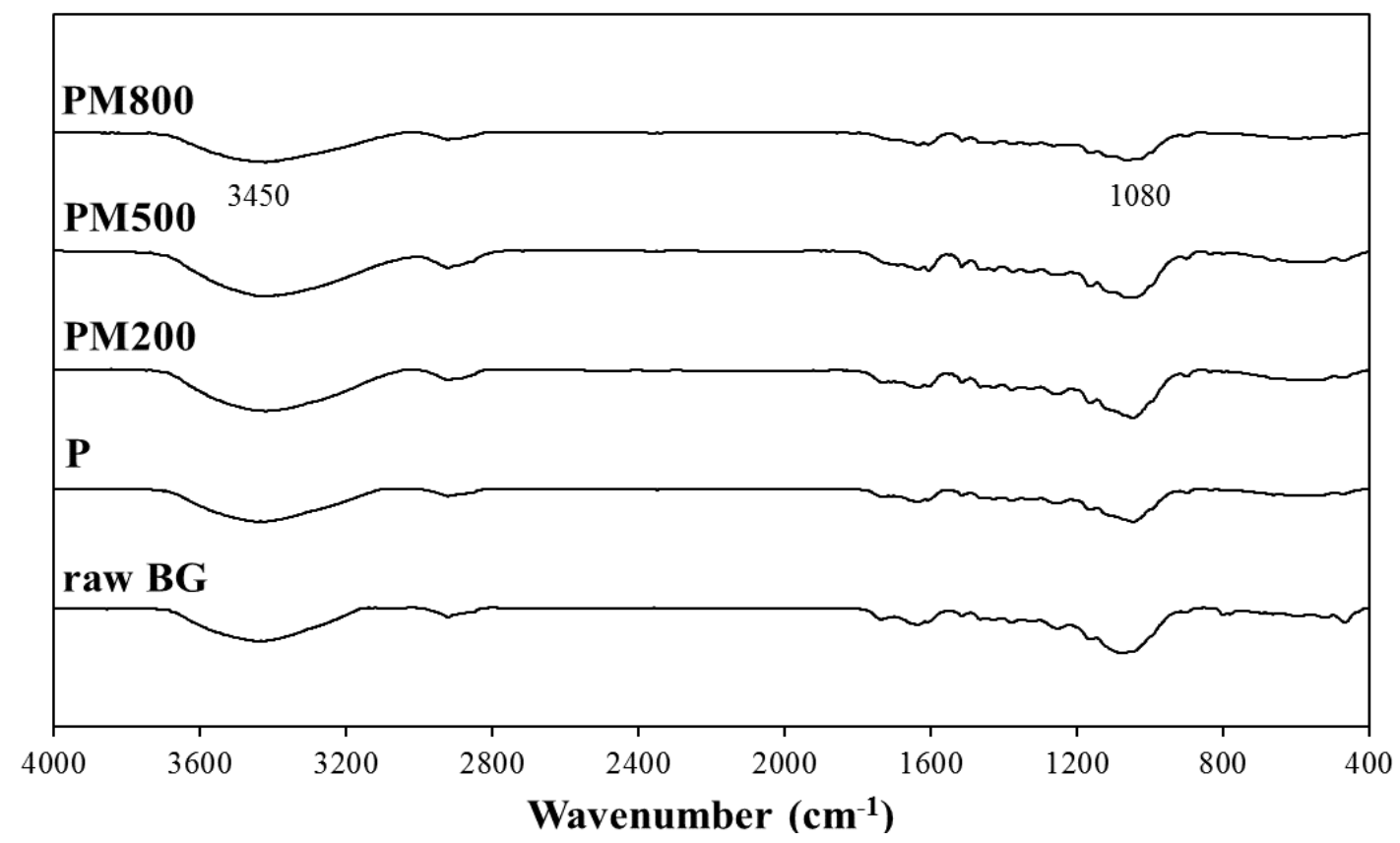

Figure 5 FTIR patterns of samples before carbonization process.

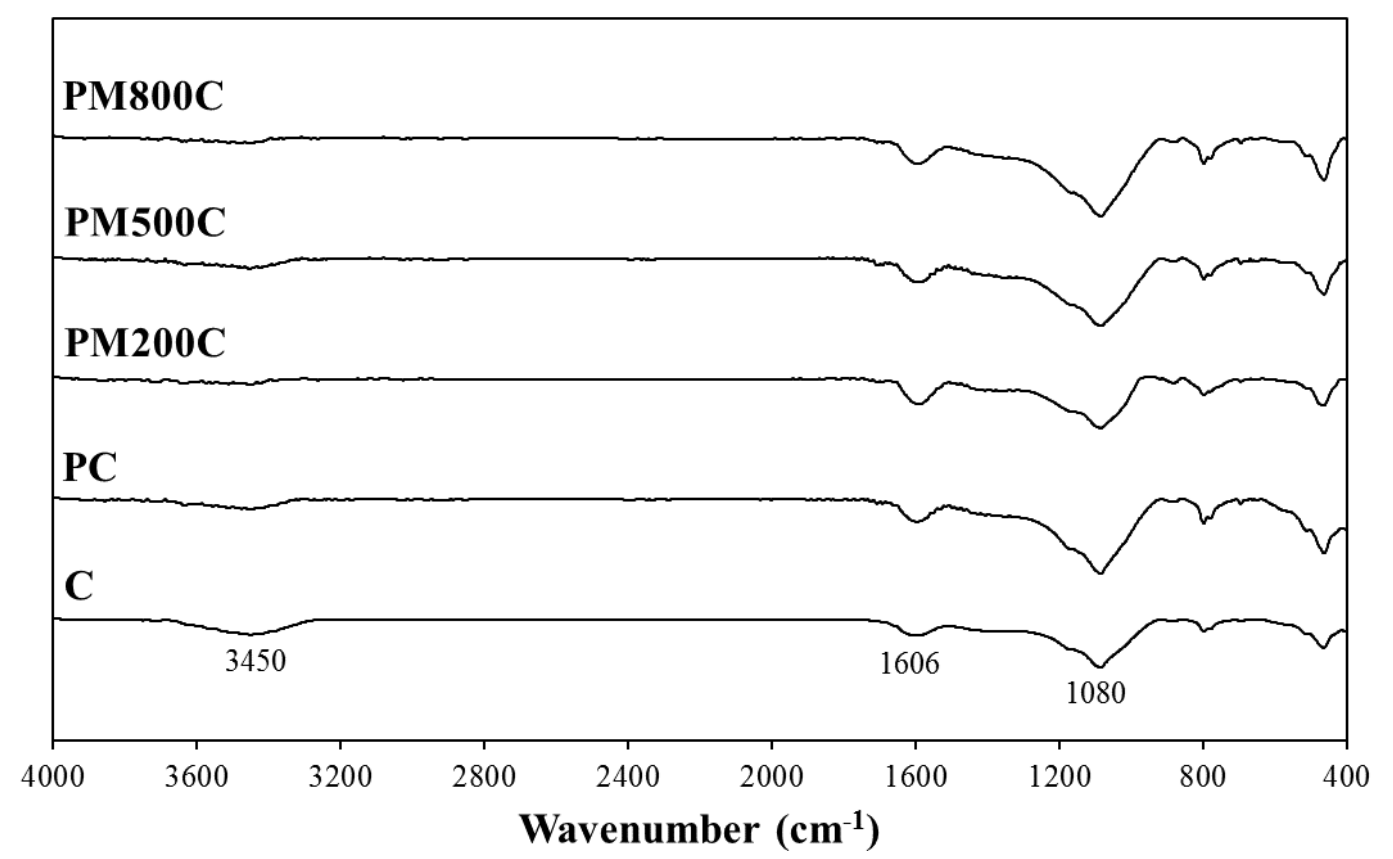

Figure 6 FTIR patterns of activated carbon from bagasse. 


\section{Surface area and isotherms}

Figure 7 shows the nitrogen adsorption isotherms of activated carbon from bagasse with/without microwave-assisted acid activation pretreatment before carbonization. Results exhibited that all of the isotherms were type I and II according to the IUPAC classification. The initial part of the isotherms is represented as type I with $\mathrm{N}_{2}$ uptake at low relative pressure, corresponding to adsorption within their micropores. For intermediate and high relative pressure, the isotherms were type II, which obtained a distribution of pore sizes (pore size larger than micropores). This finding agrees with the average pore size, as given in Figure 8(c). According to IUPAC classification, this finding of the average pore size lower than $20 \mathrm{~A}^{\circ}(2 \mathrm{~nm})$ in all samples is classified as micropore (microporous materials having pore diameters up to $\left.20 \mathrm{~A}^{\circ}(2 \mathrm{~nm})\right)$ [30].

Increasing the microwave energy up to $500 \mathrm{~W}$ resulted in a gradual increase in the $\mathrm{N}_{2}$ adsorption, surface area, and pore volume, as illustrated in Figures 7 and 8(a) - 8(b). A similar finding was performed by [29], who noted that the development of pore structure was dependent on microwave energy. Based on conventional heating, the heat source heats the carbon materials from the outer surface to its interior via convection, conduction, and radiation mechanisms, which could be non-uniform heating under the difference in the shapes and sizes of carbon materials. Consequently, some volatile components might remain inside the carbon material particles, and provide relatively low total pore volume and BET surface area [6]. Meanwhile, microwave heating is characterized as uniform and volumetric heating, the mechanism of microwave heating affects depolarization and polarization. The carbon materials receive energy through dipole rotation and ionic conduction, and large amounts of heat can be transferred from the interior to the outer surface. Hence, some volatile components that remain inside are eliminated, resulting in pore structure development and a high BET surface area is obtained. However, if the microwave energy is too high (at $800 \mathrm{~W}$ ), this leads to a reduction in the $\mathrm{N}_{2}$ adsorption and surface area, including pore volume [12,31-33]. Thus, it can be concluded that the activation using phosphoric acid with microwave energy at $500 \mathrm{~W}$ was adequate to develop the highest surface area and $\mathrm{N}_{2}$ adsorption, including fixed carbon, among the range of activation conditions used in our study.

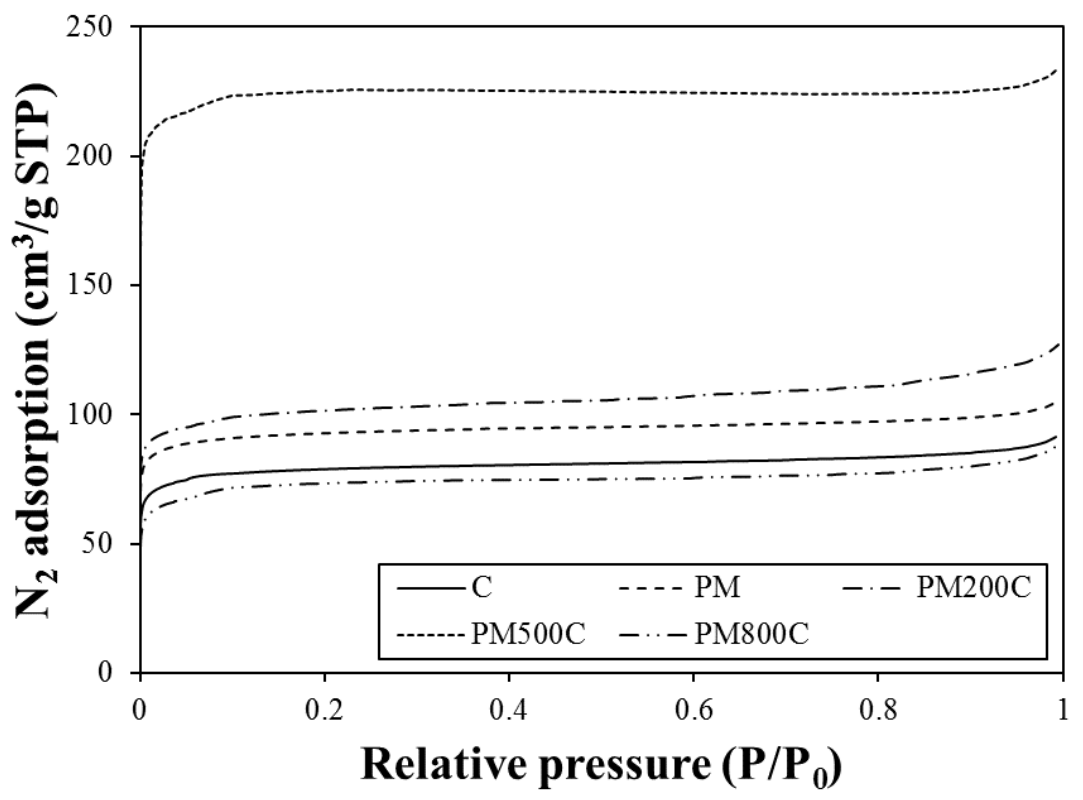

Figure 7 Nitrogen adsorption isotherms of activated carbons from bagasse by various activated conditions. 


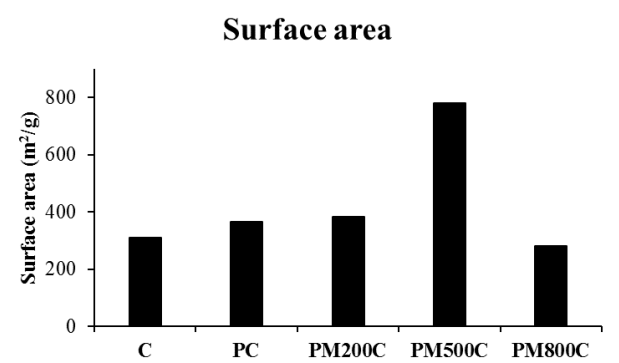

(a)

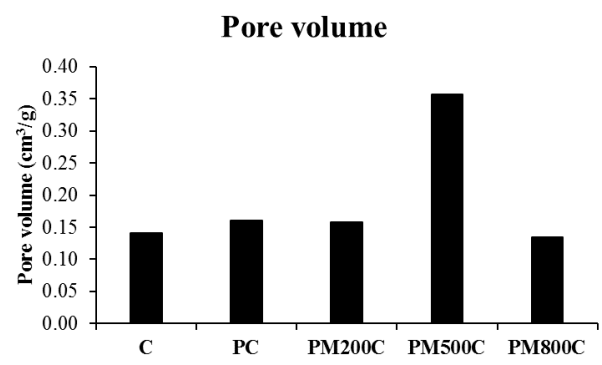

(b)

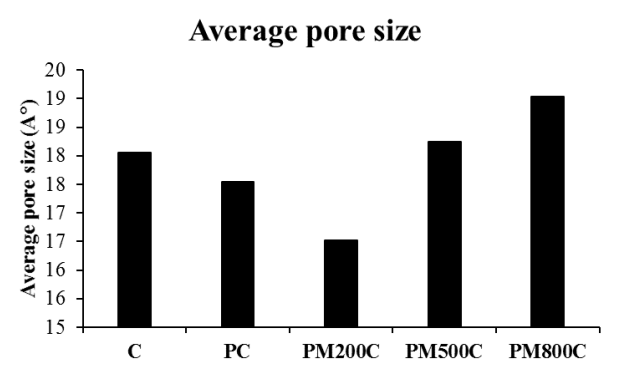

(c)

Figure 8 Results of BET analysis. (a) surface area, (b) total pore volume, and (c) average pore size.

\section{Scanning electron microscopy}

The morphology of AC obtained in this study was examined using a scanning electron microscope (SEM), as shown in Figure 9. Figure 9(a) shows sphere pores distributed on the surface of a sample without activation, due to the elimination of volatile matter after the carbonization process [34]. The activated samples (Figures 9(b) - 9(e)) also exhibited a porous structure and size similar to the control sample. This means that pretreatment with microwave energy does not affect the pore shape and size of $\mathrm{AC}$ obtained. This investigation is related to the BET results.

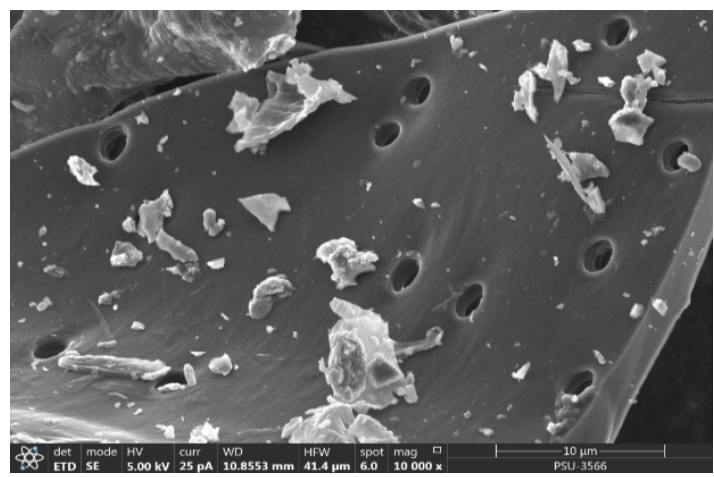

(a)

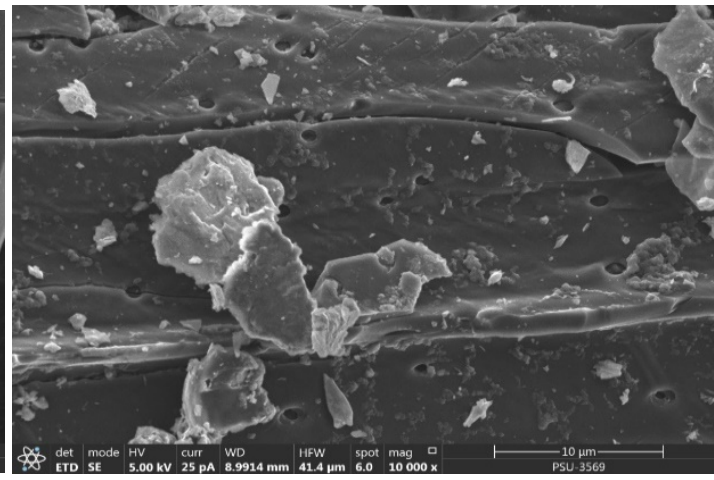

(b) 


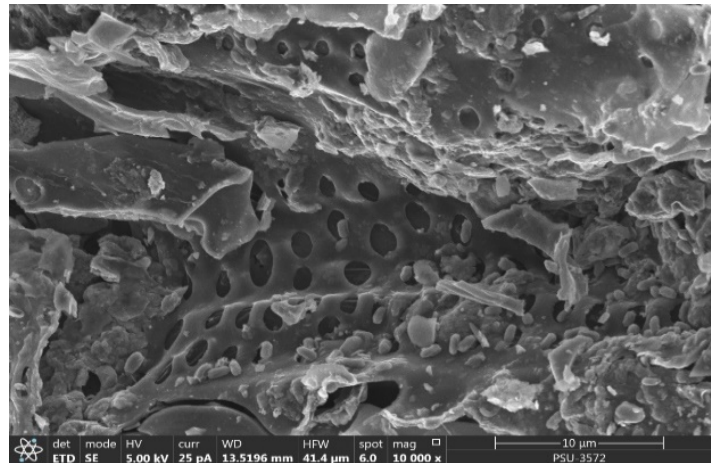

(c)

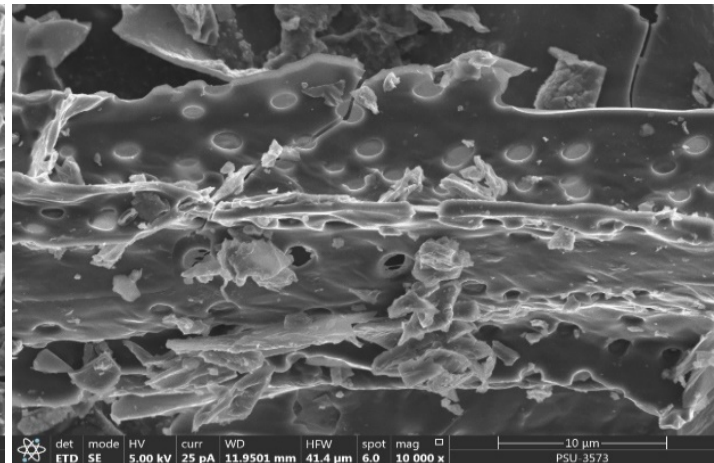

(d)

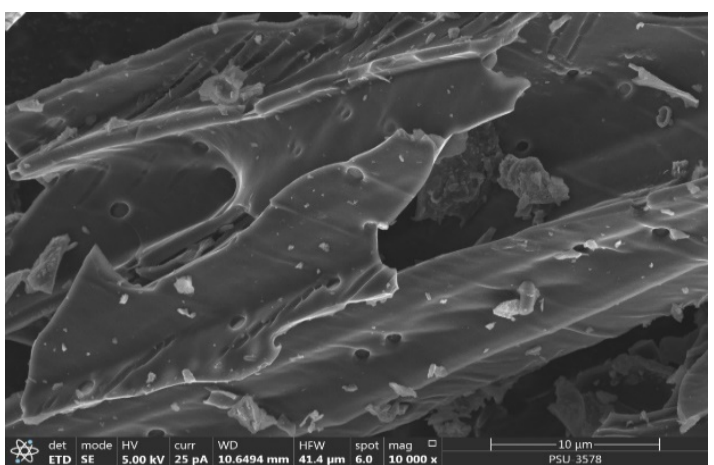

(e)

Figure 9 Morphology of activated carbon from bagasse. (a) C, (b) PC, (c) PM200C, (d) PM500C and (e) PM800C.

\section{Iodine absorption capacity}

Typically, the adsorption capacity depends on the amounts of active sites and the porous structure of AC materials $[5,13]$. The highly porous structure of AC can provide many sites for adsorption, which corresponds to high adsorption efficiency. In this research, the iodine adsorption capacity test was based on the ASTM D4607-94 approach [35], as illustrated in Figure 10. Results found that the iodine adsorption capacity was enhanced with the activated process and microwave energy, except at $800 \mathrm{~W}$. The AC prepared by pretreating phosphoric acid with $500 \mathrm{~W}$ microwave energy achieved the highest iodine adsorption efficiency of $852 \pm 6.0 \mathrm{mg} / \mathrm{g}$. Microwave energy over $500 \mathrm{~W}$ attributed to iodine adsorption capacity loss, approximately $281 \pm 6.2 \mathrm{mg} / \mathrm{g}$, due to the destruction of the pore structure [13]. This finding corroborated with the surface area and pore volume results, as represented in Figures 8(a) 8(b). 


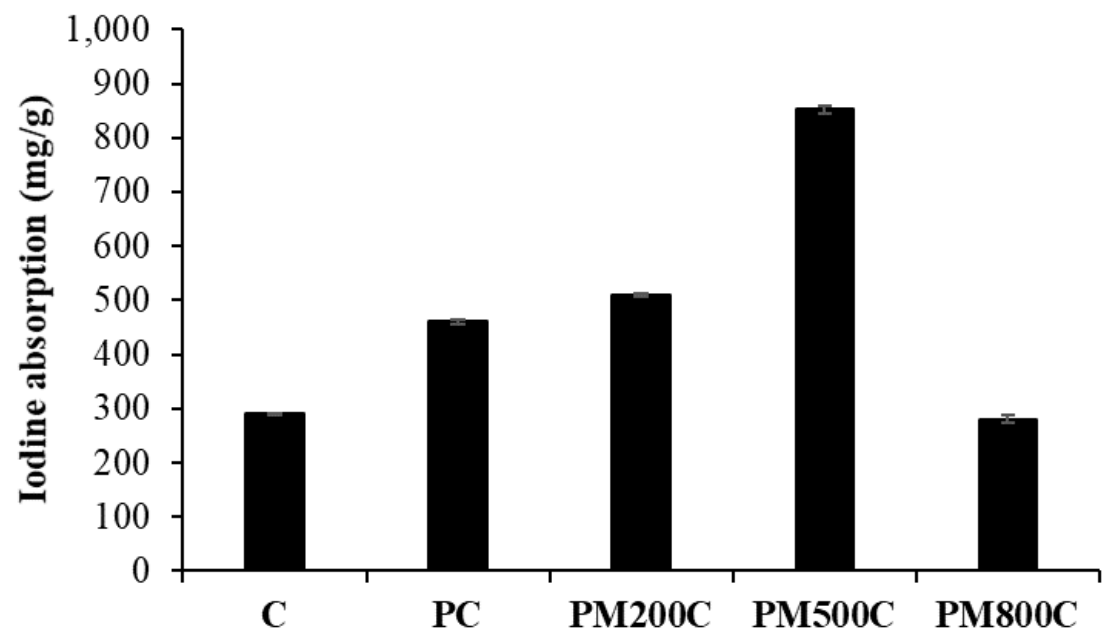

Figure 10 Iodine adsorption capacities of activated carbon.

\section{Comparison of the $\mathrm{AC}$ produced from various applications of microwave energy}

Table 2 shows the comparison of AC obtained in this study with the relevant literature through the preparation method and surface area. The AC obtained exhibited that the application of microwaveassisted phosphoric acid for pretreatment provided the AC with a high surface area of $781 \mathrm{~m}^{2} / \mathrm{g}$. Meanwhile, using microwave energy as an activation source after the carbonized process produced a similar grade of AC with a surface area in the range of $570-617 \mathrm{~m}^{2} / \mathrm{g}$. This denotes that the pretreatment by microwave-assisted phosphoric acid was a potential method for the preparation of a high-grade AC. However, previous research studies recommend that the AC produced by microwave heating (carbonized process) has more efficiency than conventional heating, as represented in surface areas above $790 \mathrm{~m}^{2} / \mathrm{g}$. This can be applied in the future study to the preparation method of AC using microwave-assisted phosphoric acid for pretreatment before carbonization by microwave heating. In addition, the other characteristics, such as recyclability and other pollutant absorption capacities, will be investigated in the future to confirm the properties of AC prepared under such conditions, and whether it can be used in the production of commercial absorbent materials.

Table 2 Comparison of AC obtained in this study with the literature.

\begin{tabular}{|c|c|c|c|}
\hline Raw material & Preparation method & Surface area $\left(\mathrm{m}^{2} / \mathrm{g}\right)$ & Reference \\
\hline Bagasse & $\begin{array}{l}\mathrm{H}_{3} \mathrm{PO}_{4} \text { with microwave energy } \\
\text { pretreatment, Conventional heating }\end{array}$ & 781 & This study \\
\hline Starch & $\begin{array}{l}\mathrm{H}_{3} \mathrm{PO}_{4} \text { with hydrothermal pretreatment, } \\
\mathrm{KOH} \text { with microwave energy activation }\end{array}$ & 616.8 & {$[11]$} \\
\hline Waste palm shell & $\begin{array}{l}\text { Microwave heating, Microwave steam } \\
\text { activation }\end{array}$ & 570.8 & {$[5]$} \\
\hline Bamboo & $\mathrm{H}_{3} \mathrm{PO}_{4}$ pretreatment, Microwave heating & 1432 & {$[29]$} \\
\hline Cotton stalk & $\mathrm{ZnCl}_{2}$ pretreatment, Microwave heating & 794.8 & {$[12]$} \\
\hline Almond shell & $\begin{array}{l}\mathrm{H}_{3} \mathrm{PO}_{4} \text { pretreatment, Microwave, and } \\
\text { Conventional heating }\end{array}$ & 1128 & {$[36]$} \\
\hline Almond shell & Microwave heating, $\mathrm{ZnCl}_{2}$ activation & 839 & {$[37]$} \\
\hline Pinecone & Microwave heating, $\mathrm{ZnCl}_{2}$ activation & 939 & {$[38]$} \\
\hline
\end{tabular}




\section{Conclusions}

The research indicates the high efficiency of AC obtained from bagasse by microwave-assisted phosphoric acid activation. The microwave energy combined with phosphoric acid for activation exhibited a relatively high potential than only phosphoric acid activation. However, the high microwave energy at $800 \mathrm{~W}$ has a negative impact on the properties of the AC obtained. The optimum activation condition in this research was microwave energy at $500 \mathrm{~W}$ with phosphoric acid which exhibited a high surface area of $781 \mathrm{~m}^{2} / \mathrm{g}$, and fixed carbon of $88.34 \pm 0.67 \%$. Such a high surface area resulted in the highest iodine adsorption of $852 \pm 6.0 \mathrm{mg} / \mathrm{g}$. Also, the AC obtained in this study exhibited microporous materials, which will be an excellent absorbent material for volatile pollutants removal. This will open the door for the application of this type of AC obtained for commercial absorbent material in the future. Thus, the overall results demonstrated that the activation under microwave-assisted a phosphoric acid is a remarkable approach for converting bagasse into AC with a high surface area and adsorption capacity.

\section{Acknowledgements}

The authors appreciate the financial support provided by Walailak University under contract WU_IRG61_32. Ms. Narinthip Suksompong is gratefully acknowledged for her hard-working assistance with the experiments. Moreover, the authors would like to express our sincere gratitude to the Science Laboratory for Education Division, Mahidol University, Kanchanaburi Campus, for research equipment and facilities.

\section{References}

[1] RV Ramanujan, S Purushotham and MH Chia. Processing and characterization of activated carbon coated magnetic particles for biomedical applications. Mater. Sci. Eng. C 2007; 27, 659-64.

[2] C Liu, BB Koyyalamudi, L Li, S Emani, C Wang and LL Shaw. Improved capacitive energy storage via surface functionalization of activated carbon as cathodes for lithium ion capacitors. Carbon 2016; 109, 163-72.

[3] RK Liew, C Chai, PNY Yek, XY Phang, MY Chong, WL Nam, MH Su, WH Lam, NL Ma and SS Lam. Innovative production of highly porous carbon for industrial effluent remediation via microwave vacuum pyrolysis plus sodium-potassium hydroxide mixture activation. J. Clean. Prod. 2019; 208, 1436-45.

[4] T Feng, M Huo, X Zhao, T Wang, X Xia and C Ma. Reduction of $\mathrm{SO}_{2}$ to elemental sulfur with $\mathrm{H}_{2}$ and mixed $\mathrm{H}_{2} / \mathrm{CO}$ gas in an activated carbon bed. Chem. Eng. Res. Des. 2017; 121, 191-9.

[5] PNY Yek, RK Liew, MS Osman, CL Lee, JH Chuah, YK Park and SS Lam. Microwave steam activation, an innovative pyrolysis approach to convert waste palm shell into highly microporous activated carbon. J. Environ. Manag. 2019; 236, 245-53.

[6] W Ao, J Fu, X Mao, Q Kang, C Ran, Y Liu, H Zhang, Z Gao, J Li, G Liu and J Dai. Microwave assisted preparation of activated carbon from biomass: A review. Renew. Sustain. Energ. Rev. 2018; 92, 958-79.

[7] M Myglovets, OI Poddubnaya, O Sevastyanova, ME Lindström, B Gawdzik, M Sobiesiak, MM Tsyba, VI Sapsay, DO Klymchuk and AM Puziy. Preparation of carbon adsorbents from lignosulfonate by phosphoric acid activation for the adsorption of metal ions. Carbon 2014; 80, 771-83.

[8] S Chandrasekaran, T Basak and R Srinivasan. Microwave heating characteristics of graphite based powder mixtures. Int. Comm. Heat Mass Tran. 2013; 48, 22-7.

[9] Y Fernández and JA Menéndez. Influence of feed characteristics on the microwave-assisted pyrolysis used to produce syngas from biomass wastes. J. Anal. Appl. Pyrol. 2011; 91, 316-22.

[10] S Ren, H Lei, L Wang, Q Bu, S Chen, J Wu, J Julson and R Ruan. Biofuel production and kinetics analysis for microwave pyrolysis of Douglas fir sawdust pellet. J. Anal. Appl. Pyrol. 2012; 94, 16369. 
[11] P Liu, Z Wu, X Ge and X Yang. Hydrothermal synthesis and microwave-assisted activation of starch-derived carbons as an effective adsorbent for naphthalene removal. $R S C A d v .2019 ;$ 9, 11696706.

[12] H Deng, L Yang, G Tao and J Dai. Preparation and characterization of activated carbon from cotton stalk by microwave assisted chemical activation: Application in methylene blue adsorption from aqueous solution. J. Hazard. Mater. 2009; 166, 1514-21.

[13] S Cheng, L Zhang, H Xia, J Peng, J Shu and C Li. Ultrasound and microwave-assisted preparation of Fe-activated carbon as an effective low-cost adsorbent for dyes wastewater treatment. RSC $A d v$. 2016; 6, 78936-46.

[14] J Bian, F Peng, XP Peng, P Peng, F Xu and RC Sun. Structural features and antioxidant activity of xylooligosaccharides enzymatically produced from sugarcane bagasse. Bioresource Tech. 2013; 127, 236-41.

[15] EF Mohamed, MA El-Hashemy, NM Abdel-Latif and WH Shetaya. Production of sugarcane bagasse-based activated carbon for formaldehyde gas removal from potted plants exposure chamber. J. Air Waste Manag. Assoc. 2015; 65, 1413-20.

[16] RH Hesas, A Arami-Niya, WMAW Daud and JN Sahu. Preparation and characterization of activated carbon from apple waste by microwave-assisted phosphoric acid activation: Application in methylene blue adsorption. Bioresources 2013; 8, 2950-66.

[17] NM Mubarak, JN Sahu, EC Abdullah, NS Jayakumar and P Ganesan. Microwave assisted multiwall carbon nanotubes enhancing $\mathrm{Cd}(\mathrm{II})$ adsorption capacity in aqueous media. J. Ind. Eng. Chem. 2015; 24, 24-33.

[18] LE Wise, M Murphy and AAD Adieco. Chlorite holocellulose, its fractionation and bearing on summative wood analysis and studies on the hemicelluloses, Vance, Illinois, 1946.

[19] TAPPI standard T 203 om-93. Alpha-, beta- and gamma-cellulose in pulp and wood. 1998.

[20] TAPPI standard T 222 om-98. Acid insoluble lignin in wood and pulp. 1998.

[21] TAPPI standard T 264 om-97. Preparation of wood for chemical analysis. 1997.

[22] C Aguilar, R García, G Soto-Garrido and R Arriagada. Catalytic wet air oxidation of aqueous ammonia with activated carbon. Appl. Catal. B. Environ. 2003; 46, 229-37.

[23] ANA El-Hendawy. Influence of $\mathrm{HNO}_{3}$ oxidation on the structure and adsorptive properties of corncob-based activated carbon. Carbon 2003; 41, 713-22.

[24] C Moreno-Castilla, MV López-Ramón and F Carrasco-Marín. Changes in surface chemistry of activated carbons by wet oxidation. Carbon 2000; 38, 1995-2001.

[25] V Boonamnuayvitaya, S Sae-ung and W Tanthapanichakoon. Preparation of activated carbons from coffee residue for the adsorption of formaldehyde. Separ. Purif. Tech. 2005; 42, 159-68.

[26] SW Hao, CH Hsu, YG Liu and BK Chang. Activated carbon derived from hydrothermal treatment of sucrose and its air filtration application. RSC Adv. 2016; 6, 109950-9.

[27] H Mao, D Zhou, Z Hashisho, S Wang, H Chen, H Wang and MJ Lashaki. Microporous activated carbon from pinewood and wheat straw by microwave-assisted $\mathrm{KOH}$ treatment for the adsorption of toluene and acetone vapors. RSC Adv. 2015; 5, 36051-8.

[28] AM Puziy, OI Poddubnaya, RP Socha, J Gurgul and M Wisniewski. XPS and NMR studies of phosphoric acid activated carbons. Carbon 2008; 46, 2113-23.

[29] QS Liu, T Zheng, P Wang and L Guo. Preparation and characterization of activated carbon from bamboo by microwave-induced phosphoric acid activation. Ind. Crop. Prod. 2010; 31, 233-8.

[30] KSW Sing. Characterization of porous solids: An introductory survey. Stud. Surf. Sci. Catal. 1991; 62, 1-9.

[31] KY Foo and BH Hameed. Coconut husk derived activated carbon via microwave induced activation: Effects of activation agents, preparation parameters and adsorption performance. Chem. Eng. J. 2012; 184, 57-65.

[32] W Li, LB Zhang, JH Peng, N Li and XY Zhu. Preparation of high surface area activated carbons from tobacco stems with $\mathrm{K}_{2} \mathrm{CO}_{3}$ activation using microwave radiation. Ind. Crop. Prod. 2008; 27, $341-7$. 
http://wjst.wu.ac.th

[33] KY Foo and BH Hameed. Mesoporous activated carbon from wood sawdust by $\mathrm{K}_{2} \mathrm{CO}_{3}$ activation using microwave heating. Bioresource Tech. 2012; 111, 425-32.

[34] M Asadieraghi and WMA Wan Daud. Characterization of lignocellulosic biomass thermal degradation and physiochemical structure: Effects of demineralization by diverse acid solutions. Energ. Convers. Manag. 2014; 82, 71-82.

[35] ASTM International. ASTM D4607-14: Standard test method for determination of iodine number of activated carbon, ASTM International, Pennsylvania, 2014.

[36] MS İzgi, C Saka, O Baytar, G Saraçoğlu and Ö Şahin. Preparation and characterization of activated carbon from microwave and conventional heated almond shells using phosphoric acid activation. Anal. Lett. 2019; 52, 772-89.

[37] D Chunfeng, Y Hongbing, W Zhansheng, G Xinyu, C Giancarlo, Y Bang-Ce and K Imdad. Microwave-assisted preparation of almond shell-based activated carbon for methylene blue adsorption. Green Process. Synth. 2016; 5, 395-406.

[38] A Özhan, Ö Şahin, MM Küçük and C Saka. Preparation and characterization of activated carbon from pine cone by microwave-induced $\mathrm{ZnCl}_{2}$ activation and its effects on the adsorption of methylene blue. Cellulose 2014; 21, 2457-67. 